\begin{tabular}{|c|c|}
\hline $\begin{array}{l}\text { Випасняк Ігор Петрович - доктор наук з фізич- } \\
\text { ного виховання і спорту, професор, ДВНЗ “При- } \\
\text { карпатський національний університет імені Ва- } \\
\text { силя Стефаника" (Івано-Франківськ, Україна) }\end{array}$ & $\begin{array}{l}\text { Vypasnyak Ihor Petrovych - Doctor of Science in } \\
\text { Physical Education and Sports, Professor, Vasyl } \\
\text { Stefanyk Precarpathian National University (Ivano- } \\
\text { Frankivsk, Ukraine) }\end{array}$ \\
\hline \multicolumn{2}{|l|}{$\begin{array}{l}\text { e-mail: kicuk80@ gmail.com } \\
\text { https://orcid.org/0000-0002-4192-1880 }\end{array}$} \\
\hline $\begin{array}{l}\text { Лесів Мар’яна Зіновївна - аспірант, ДВНЗ “При- } \\
\text { карпатський національний університет імені Ва- } \\
\text { силя Стефаника" (Івано-Франківськ, Україна) }\end{array}$ & $\begin{array}{l}\text { Lesiv Mariana Zinoviivna - post-graduate student, } \\
\text { Vasyl Stefanyk Precarpathian National University } \\
\text { (Ivano-Frankivsk, Ukraine) }\end{array}$ \\
\hline
\end{tabular}

\section{УДК [797.217+796.015.576]: 612.2-055.2 doi: 10.15330/fcult.35.78-83}

\section{Юрій Фурман, Вікторія Головкіна,} Світлана Сальникова, Юрій Довгій

\title{
ВПЛИВ ЕЛЕМЕНТІВ АКВАФІТНЕСУ Й ІНТЕРВАЛЬНОГО ГІПОКСИЧНОГО ДИХАННЯ НА ДИНАМІКУ ВІДНОВЛЕННЯ ФУНКЩІЇ СЕРЦЕВО-СУДИННОЇ СИСТЕМИ ЮНИХ ПЛАВЦІВ
}

\begin{abstract}
Мета. Встановити комплексний вплив тренувальних занять, з аквафітнесу та інтервального гіпоксичного дихання на відновлення функиї серцево-судинної системи у юних плавців після стандартного фізичного навантаження. Методи. у дослідженні брали участь 64 спортсмени чоловічої статі віком 11-12 років, спортивний стаж яких становив 2-3 роки. Протягом 24 тижнів на різних етапах дослідження (через 8, 16 та 24 тижні) вивчалася динаміка відновлення частоти серчевих скорочень після дозованих фізичних навантажень у осіб, які застосовували в навчально-тренувальному процесі елементи аквафітнесу й методики інтервального гіпоксичного дихання. Результати. Встановлено, щзо застосування елементів аквафітнесу й методики інтервального гіпоксичного дихання зі спортсменами основної групи прискорює відновлення показників частоти сериевих скорочень після навантажень циклічного характеру. Висновок. Отже, виявлений позитивний ефект поєднаного впливу аквафітнесу й інтервального гіпоксичного дихання на процеси відновлення функиії серцево-судинної системи після стандартних фізичних навантажень дає підстави стверджувати, щзо иі засоби забезпечують прискорене формування струтурно-функціонального сліду адаптаціï юних плавців до аеробних фізичних навантажень і сприяють удосконаленню нейрогенних механізмі регуляиї серцево-судинної системи.

Ключові слова: плавиі, частота сериевих скорочень, відновлення, інтервальне гіпоксичне дихання, аквафітнес.
\end{abstract}

Aim. To establish the complex effect of training sessions on aqua fitness and interval hypoxic breathing on the restoration of cardiovascular function in young swimmers after standard exercise. Material, The study involved 62 athletes aged 11-12 years, whose sports experience was 2-3 years. During 24 weeks at different stages of the study $(8,16$ and 24 weeks) studied the dynamics of recovery of heart rate after dosed exercise in individuals who used in the training process elements of aqua fitness and interval hypoxic respiration techniques. It is established that the use of elements of aqua fitness and interval hypoxic respiration techniques with athletes of the main group accelerates the recovery of heart rate after exercise of a cyclical nature. Results. The growth of results in all sports is due to increased efficiency of training sessions due to the introduction of the latest technologies in the systematic training of athletes. The health-improving effect of physical exercises in water is due to the high energy cost of work, the phenomenon of gravitational unloading of the body, the positive effect on the cardiovascular and respiratory systems, the presence of a stable hardening effect. Taking into account the experience of previous researchers, we predicted that the integrated application of the technique of interval hypoxic respiration and elements of aqua fitness in the training process of young swimmers will help improve their functional and physical fitness. Conclusions. Thus, the positive effect of the combined effect of aquafitness and interval hypoxic respiration on the recovery of cardiovascular function after standard exercise suggests that these tools provide accelerated formation of structural and functional trace of adaptation of young swimmers to aerobic exercise and contribute to improved regulation of the cardiovascular system.

Key words: swimmers, the frequency of heart constraction, a recuperation, interval hypoxic respiration, aquafitness 
Постановка проблеми та аналіз результатів останніх досліджень. Найбільш актуальною проблемою спорту вищих досягнень $є$ питання підготовки спортивного резерву, зокрема, у плаванні. Тому на початкових етапах багаторічної підготовки плавців тренувальний процес повинен здійснюватися з урахуванням вікових функціональних можливостей спортсменів [6, 7, 9], що позитивно відображається на адаптаційній перебудові організму $[8,10]$.

Функціональні можливості людини лімітуються енергетичним потенціалом організму $[1,9,10,11]$ та здатністю адаптуватися до впливу різних чинників зовнішнього середовища [1], зокрема до фізичної роботи. На етапі попередньої базової підготовки удосконалення функціональної підготовленості плавців відбувається на фоні інтенсивної вікової перебудови організму $[2,3,9]$. Застосування на цьому етапі багаторічної підготовки тренувальних навантажень без урахування швидкої динаміки морфофункціональних змін організму може не лише негативно вплинути на спортивні результати, але й порушити природну вікову динаміку вдосконалення адаптаційних процесів [2, 3, 9].

Зростання результатів з усіх видів спорту зумовлене підвищенням ефективності навчально-тренувальних занять за рахунок впровадження в системній підготовці спортсменів новітніх технологій. Оздоровча дія фізичних вправ у воді пов'язана 3 високою енергетичною вартістю роботи, гравітаційним розвантаженням тіла, позитивним впливом на функцію серцево-судинної та дихальної систем, наявністю стійкого ефекту загартовування. Беручи до уваги досвід напрацювань попередніх дослідників, ми передбачили, що комплексне застосування методики інтервального гіпоксичного дихання (ІГД) й елементів аквафітнесу в тренувальному процесі юних спортсменівплавців сприятиме підвищенню їх функціональної та фізичної підготовленості.

Аналіз протоколів Ігор Олімпіад, Чемпіонатів Світу та інших змагань свідчить про динаміку зростання результатів з усіх видів спорту [2, 3].

За даними ряду науковців виконання фізичних вправ у воді позитивно впливає на різні функціональні системи організму $[3,9]$. Оздоровча дія фізичних вправ у воді обумовлена високою енергетичною вартістю роботи, гравітаційним розвантаженням тіла, позитивною дією на серцево-судинну і дихальну системи, наявністю стійкого ефекту загартовування [3,6].

У практиці фізичного виховання при роботі 3 особами різного віку застосовуються допоміжні засоби, які посилюють ефективність фізичних вправ. Зокрема, результати досліджень Ю.М. Фурмана, Н.В. Гаврилової, І.В. Грузевич $[2,3,7]$ засвідчили, що комплексне застосування методики ендогенно-гіпоксичного дихання за допомогою апарату “Ендогенік-01” і фізичних навантажень у навчально-тренувальному процесі юних спортсменів покращує функціональні можливості дихальної системи, сприяє підвищенню фізичної працездатності, аеробної та анаеробної продуктивності організму.

Крім того, проведені Ю.М. Фурманом та С.В. Сальниковою [7] дослідження довели ефективність комплексного застосування аквафітнесу і методики ендогенно-гіпоксичного дихання при роботі з жінками зрілого віку, що підтверджено покращенням їх фізичного стану.

3 огляду на вищевикладене, в програму тренувальних занять плавців ми пропонуємо інтегрувати елементи аквафітнесу й метод інтервального гіпоксичного дихання (ІГД) з використанням апарату “Ендогенік-01” (Г.І. Ходоровський зі спів., 2004) $[2,5]$.

Зв'язок проблеми 3 важливими науковими завданнями. Беручи до уваги досвід напрацювань попередніх дослідників [2, 5], ми передбачили, що комплексне 
застосування методики ІГД й елементів аквафітнесу в тренувальному процесі юних спортсменів-плавців сприятиме підвищенню їх функціональної та фізичної підготовленості $[6,7]$. Важливим показником рівня адаптації серцево-судинної системи спортсмена до фізичних навантажень $є$ період відновлення показників частоти серцевих скорочень (ЧСС) після фізичних навантажень. Період відновлення ЧСС після фізичної роботи можна використовувати як критерії оцінки функціональної підготовленості - 3 покращенням функціональної підготовленості період відновлення зменшується [8].

Мета дослідження - встановити комплексний вплив тренувальних занять, 3 аквафітнесу та інтервального гіпоксичного дихання на відновлення функції серцевосудинної системи у юних плавців після стандартного фізичного навантаження.

Методи дослідження. Для визначення відновлення функції серцево-судинної системи у плавців вимірювали частоту серцевих скорочень за допомогою монітора серцевого ритму “Beurer PM 70" у стані відносного м'язового спокою. Далі досліджувані послідовно виконували на велоергометрі два навантаження помірної інтенсивності з частотою педалювання 60-70 об.ххв. ${ }^{-1}$, Потужність роботи, яка розраховувалася в залежності від ваги тіла спортсмена, встановлювали на дисплеї. Під час першого навантаження потужність становила близько 1 Вт/кг ваги тіла досліджуваного, а другого - 2 Вт/кг ваги тіла. Одразу після завершення першого та другого навантажень, а також після сплину першої, другої та третьої хвилин відновлювального періоду реєстрували частоту серцевих скорочень.

Для визначення ефективності впливу комплексного застосування фізичного навантаження і методики ІГД на фізичну підготовленість юних плавців ми порівнювали середні арифметичні значення пов'язаних вибірок, а достовірні відмінності між ними визначали за критерієм Стьюдента [4].

Дослідження здійснювалося в лабораторії кафедри медико-біологічних основ фізичного виховання та фізичної реабілітації Вінницького державного педагогічного університету імені Михайла Коцюбинського. Обстеження проводили в першій половині дня між 9 і 13 годинами.

Педагогічний експеримент тривав протягом 24 тижнів підготовчого періоду річного макроциклу в чотири етапи: до початку експерименту, через 8, 16 та 24 тижні після його початку. У ньому брали участь 64 юні плавці чоловічої статі, віом 11-12 років 3 кваліфікацією третього спортивного розряду. Спортсменів перед початком формувального експерименту розділили на три групи - контрольну $(К Г, \mathrm{n}=21)$ i дві основні $(\mathrm{O} 1, \mathrm{n}=21$; ОГ2, $\mathrm{n}=22)$. Всі плавці займалися 6 разів на тиждень за навчальною програмою для ДЮСШ. Спортсмени основних груп застосовували на кожному занятті під час розминки на суші методику інтервального гіпоксичного тренування із використанням апарату "Ендогенік - 01", відповідно до так званих "маршрутних карт" $[3,5]$, що дозволяло поступово адаптуватися до нормобаричної гіперкапнічної гіпоксії протягом усього експерименту. Разом з тим, частину часу, відведеного за програмою ДЮСШ з плавання для силової підготовки в залі сухого плавання, для досліджуваних спортсменів основної групи ОГ2 ми замінили заняттями (20 хвилин) аквафітнесом наприкінці тренувального заняття.

Результати дослідження. Як свідчать результати досліджень, проведених до початку занять, у представників контрольної (КГ), та основних (ОГ1, ОГ2) груп відновлення ЧСС після виконання роботи потужністю 1 Вт·кг ${ }^{-1}$ відбувалося на третій хвилині відновлювального періоду. Після 8-ми тижнів від початку педагогічного експерименту спостерігалася позитивна динаміка відновлення ЧСС після виконання

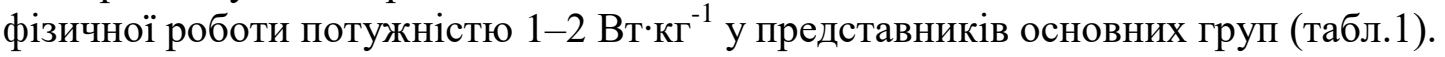


Фурман Юрій, Головкіна Вікторія, Сальникова Світлана, Довгій Юрій. Вплив елементів аквафітнесу ...

Таблиия 1

Динаміка відновлення частоти серцевих скорочень юних спортсменів 11-12 років після дозованих фізичних навантажень на різних етапах педагогічного експерименту

\begin{tabular}{|c|c|c|c|c|c|c|}
\hline \multirow{3}{*}{$\begin{array}{c}\text { Потуж- } \\
\text { ність } \\
\text { роботи }\end{array}$} & \multirow[t]{3}{*}{ Групи } & \multicolumn{5}{|c|}{ Частота серцевих скорочень, $\overline{\mathrm{x}} \pm \mathrm{S}$} \\
\hline & & \multirow{2}{*}{\begin{tabular}{|c|} 
до \\
навантаження
\end{tabular}} & \multicolumn{4}{|c|}{ після навантаження } \\
\hline & & & одразу & через 1 хв & через 2 хв & через 3 хв \\
\hline \multicolumn{7}{|c|}{ до початку занять } \\
\hline $1 \mathrm{BT} \cdot \mathrm{K}^{-1}$ & КГ & $78,71 \pm 1,77$ & $121,14 \pm 2,60^{*}$ & $116,52 \pm 2,01^{*}$ & $96,67 \pm 2,13^{*}$ & $84,43 \pm 2,37$ \\
\hline $1 \mathrm{BT} \cdot \kappa \Gamma^{-1}$ & ОГ1 & $77,09 \pm 2,06$ & $119,64 \pm 1,83^{*}$ & $113,05 \pm 2,17 *$ & $96,91 \pm 1,31 *$ & $82,00 \pm 1,60$ \\
\hline $1 \mathrm{BT} \cdot \mathrm{K}^{-1}$ & ОГ2 & $78,81 \pm 1,89$ & $121,81 \pm 2,60^{*}$ & $115,24 \pm 2,13 *$ & $96,90 \pm 2,43 *$ & $83,67 \pm 1,77$ \\
\hline $2 \mathrm{BT} \cdot \kappa \Gamma^{-1}$ & КГ & $78,71 \pm 1,77$ & $170,19 \pm 0,41^{*}$ & $128,86 \pm 2,13 *$ & $100,19 \pm 1,72 *$ & $94,33 \pm 1,72 *$ \\
\hline $2 \mathrm{BT} \cdot \kappa \Gamma^{-1}$ & ОГ1 & $77,09 \pm 2,06$ & $169,14 \pm 0,63 *$ & $127,14 \pm 2,00 *$ & $102,95 \pm 1,60 *$ & $94,68 \pm 1,83 *$ \\
\hline $2 \mathrm{BT} \cdot \mathrm{K}^{-1}$ & ОГ2 & $78,81 \pm 1,89$ & $170,14 \pm 0,41^{*}$ & $126,29 \pm 2,01^{*}$ & $100,19 \pm 1,72 *$ & $94,33 \pm 1,72 *$ \\
\hline \multicolumn{7}{|c|}{ через 8 тижнів від початку занять } \\
\hline $1 \mathrm{BT} \cdot \mathrm{K \Gamma}^{-1}$ & КГ & $77,62 \pm 1,83$ & $118,67 \pm 1,89 *$ & $110,95 \pm 1,77^{*}$ & $92,48 \pm 2,19^{*}$ & $81,71 \pm 1,77$ \\
\hline $1 \mathrm{BT} \cdot \mathrm{Kr}^{-1}$ & $\mathrm{O} \Gamma 1$ & $76,14 \pm 2,00$ & $109,86 \pm 1,03 *$ & $104,00 \pm 1,43^{*}$ & $92,27 \pm 0,86^{*}$ & $80,59 \pm 1,60$ \\
\hline $1 \mathrm{BT} \cdot \mathrm{K}^{-1}$ & ОГ2 & $77,57 \pm 1,77$ & $118,05 \pm 1,89^{*}$ & $99,10 \pm 1,66^{*}$ & $82,52 \pm 1,66^{*}$ & $79,29 \pm 1,77$ \\
\hline $2 \mathrm{BT} \cdot \mathrm{K \Gamma}^{-1}$ & КГ & $77,62 \pm 1,83$ & $167,57 \pm 0,77 *$ & $124,95 \pm 2,07 *$ & $97,38 \pm 1,60^{*}$ & $91,38 \pm 1,89 *$ \\
\hline $2 \mathrm{BT} \cdot \kappa \Gamma^{-1}$ & ОГ1 & $76,14 \pm 2,00$ & $166,77 \pm 1,14^{*}$ & $123,14 \pm 1,83 *$ & $96,68 \pm 1,94 *$ & $88,86 \pm 1,49 *$ \\
\hline $2 \mathrm{BT} \cdot \mathrm{K \Gamma}^{-1}$ & ОГ2 & $77,57 \pm 1,77$ & $167,00 \pm 0,89 *$ & $121,90 \pm 1,48^{*}$ & $98,90 \pm 1,60^{*}$ & $92,52 \pm 1,66^{*}$ \\
\hline \multicolumn{7}{|c|}{ через 16 тижнів від початку занять } \\
\hline $1 \mathrm{BT} \cdot \mathrm{Kr}^{-1}$ & КГ & $73,57 \pm 0,83$ & $117,90 \pm 2,13 *$ & $103,38 \pm 1,66^{*}$ & $88,10 \pm 1,60^{*}$ & $76,33 \pm 1,66$ \\
\hline $1 \mathrm{BT} \cdot \mathrm{K \Gamma}^{-1}$ & ОГ1 & $75,77 \pm 1,71$ & $115,68 \pm 1,31^{*}$ & $101,18 \pm 2,00^{*}$ & $80,05 \pm 1,54$ & $78,00 \pm 1,43$ \\
\hline $1 \mathrm{BT} \cdot \kappa \Gamma^{-1}$ & ОГ2 & $73,29 \pm 0,83$ & $119,81 \pm 0,95 *$ & $93,00 \pm 1,06^{*}$ & $77,43 \pm 1,89$ & $76,24 \pm 1,89$ \\
\hline $2 \mathrm{BT} \cdot \mathrm{K}^{-1}$ & КГ & $73,57 \pm 0,83$ & $164,81 \pm 2,13^{*}$ & $121,48 \pm 1,60^{*}$ & $94,57 \pm 1,72^{*}$ & $85,86 \pm 1,42 *$ \\
\hline $2 \mathrm{BT} \cdot \mathrm{K \Gamma}^{-1}$ & ОГ1 & $75,77 \pm 1,71$ & $158,68 \pm 1,54 *$ & $119,91 \pm 2,29 *$ & $94,36 \pm 1,14^{*}$ & $87,73 \pm 1,20^{*}$ \\
\hline $2 \mathrm{BT} \cdot \mathrm{K \Gamma}^{-1}$ & ОГ2 & $73,29 \pm 0,83$ & $157,62 \pm 0,83^{*}$ & $112,90 \pm 1,48^{*}$ & $93,48 \pm 1,83^{*}$ & $85,00 \pm 1,60 *$ \\
\hline \multicolumn{7}{|c|}{ через 24 тижні від початку занять } \\
\hline $1 \mathrm{BT} \cdot \mathrm{KT}^{-1}$ & КГ & $73,43 \pm 0,83$ & $117,52 \pm 2,13 *$ & $102,95 \pm 1,66^{*}$ & $87,19 \pm 1,36^{*}$ & $73,81 \pm 0,89$ \\
\hline $1 \mathrm{BT} \cdot \kappa \Gamma^{-1}$ & ОГ1 & $74,73 \pm 1,37$ & $115,41 \pm 1,31^{*}$ & $95,73 \pm 1,43 *$ & $79,00 \pm 1,71$ & $76,14 \pm 1,37$ \\
\hline $1 \mathrm{BT} \cdot \mathrm{K}^{-1}$ & ОГ2 & $73,00 \pm 0,83$ & $119,00 \pm 1,06^{*}$ & $87,95 \pm 1,66^{*}$ & $77,00 \pm 1,89$ & $75,00 \pm 1,01$ \\
\hline $2 \mathrm{BT} \cdot \mathrm{KT}^{-1}$ & КГ & $73,43 \pm 0,83$ & $164,43 \pm 2,13 *$ & $120,48 \pm 1,60^{*}$ & $92,95 \pm 1,18^{*}$ & $86,19 \pm 1,48^{*}$ \\
\hline $2 \mathrm{BT} \cdot \mathrm{K \Gamma}^{-1}$ & ОГ1 & $74,73 \pm 1,37$ & $158,18 \pm 1,54^{*}$ & $117,82 \pm 2,06^{*}$ & $92,73 \pm 1,31^{*}$ & $85,45 \pm 1,43^{*}$ \\
\hline $2 \mathrm{BT} \cdot \mathrm{K \Gamma}^{-1}$ & ОГ2 & $73,00 \pm 0,83$ & $157,14 \pm 0,83^{*}$ & $108,29 \pm 1,18^{*}$ & $93,10 \pm 1,83^{*}$ & $84,10 \pm 1,95^{*}$ \\
\hline
\end{tabular}

Примітка. *-статистично достовірні відмінності відносно вихідних даних $(\mathrm{p}<0,05)$

Разом з тим встановлено, що відносно даних, зареєстрованих до початку виконання роботи на велоергометрі потужністю 1 Вт/кг ваги тіла, після виконання дозованої роботи у спортсменів основних груп (ОГ1, ОГ2 вірогідне відновлення ЧСС на другій хвилині відбувалося через 16 тижнів від початку занять (див. табл. 1).

Дискусія. Отримані в ході дослідження результати підтверджують наукові відомості щодо підвищення функціональних резервів кардіореспіраторної системи у юних спортсменів-плавців під впливом комплексного застосування у тренувальному процесі аквафітнесу й інтервального гіпоксичного дихання $[2,3,9]$. Водночас, можна констатувати, що аеробні навантаження у вигляді аквафітнесу у поєднанні з інтервальним гіпоксичним диханням суттєво удосконалюють механізми нервової регуляції функцій серцево-судинної системи, як і основні засоби тренувального процесу плавців $[3,6,7]$.

Висновок. Отже, виявлений позитивний ефект поєднаного впливу аквафітнесу й інтервального гіпоксичного дихання на процеси відновлення функції серцево-судинної 
системи після стандартних фізичних навантажень дає підстави стверджувати, що ці засоби забезпечують прискорене формування струтурно-функціонального сліду адаптації юних плавців до аеробних фізичних навантажень і сприяють удосконаленню нейрогенних механізмі регуляції серцево-судинної системи.

1. Апанасенко ГЛ, Попова ЛА, Магльований АВ. Санологія (Медичні аспекти валеології): підручник. Київ-Львів, 2011. 198 с.

2. Гаврилова НВ. Удосконалення функціональної та фізичної підготовленості велосипедистів 13-16 років шляхом застосування методики ендогенно-гіпоксичного дихання у підготовчому періоді річного макроциклу. Молода спортивна наука України. Львів. 2011; 5: 48-54.

3. Головкіна ВВ. Застосування елементів аквафітнесу й інтервального гіпоксичного тренування в системній підготовці плавців 11-12 років [дисертация]. Вінниця: ВДПУ ім. М. Коцюбинського, 2020. $220 \mathrm{c}$.

4. Куликов МА, Шастун СА. Статистические методы обработки результатов физиологических экспериментов. Практикум по нормальной физиологии. Москва: Высшая школа, 1983; 261-279.

5. Ходоровський ГІ, Коляско IB., Фуркал СС. та ін. Ендогенно-гіпоксичне дихання. Чернівці: Теорія і практика, 2006. 144 с. ISBN 966-697-174-7.

6. Furman YuM, Holovkina VV, Salnykova SV, Sulyma AS, Brezdeniuk OYu, Korolchuk AP, Nesterova SYu. Effect of swimming with the use of aqua fitness elements and interval hypoxic training on the physical fitness of boys aged 11-12 years. Pedagogics, psychology, medical-biological problems of physical training and sports. 2018; 22(4): 184-188. Doi: 10.15561/18189172.2018.

7. Salnykova SV, Furman YuM, Sulyma AS, Hruzevych IV, Gavrylova NV, Onyschuk VYe, Brezdeniuk OYu. Peculiarities of aqua fitness exercises influence on the physical preparedness of women 30-49 years old using endogenous-hypoxic breathing method. Pedagogics, psychology, medical-biological problems of physical training and sports. 2018; 22(4): 210-215. Doi: 10.15561/18189172.2018.0407

8. Sergiy Drachuk, Viktoriia Bohuslavska, Maryan Pityn, Yuriy Furman, Viktor Kostiukevych, Nataliia Gavrylova, Svitlana Salnykova, Tetiana Didyk, Energy supply capacity when using different exercise modes for young 17-19-year-old men, Journal of Physical Education and Sport ${ }^{\circledR}$ (JPES). 2018; 18(1): Art 33, 246-254.

9. Victoria Golovkina, Svetlana Salnukova. Comparative Characteristics of Functional Capability of 11-12 year-old Swimmers Connected with Their Gender and Possibilities of Its Improvement. Prace Naukowe Akademii im. Jana Długosza w Częstochowie Kultura Fizyczna. 2018; 1(XVII): 79-85.

10. Volodymyr Vitomskiy, Iryna Hruzevych, Svitlana Salnykova, Alla Sulyma, Volodymyr Kormiltsev, Yuriy Kyrychenko, Larysa Sarafinjuk. The physical development of children who have a functionally single heart ventricle as a basis for working physical rehabilitation technology after a hemodynamic correction. Journal of Physical Education and Sport ${ }^{\circledR}$ (JPES). 2018;Volume 89, Issue No 18(2): 614-617.

11. Volodymyr Vitomskiy, Volodymyr Kormiltsev, Iryna Hruzevych, Svitlana Salnykova, Yurii Shevchuk, Yulia Yakusheva. Features of the physical development of children with functionally single heart ventricle as a basis of the physical rehabilitation technology after a hemodynamic correction. Journal of Physical Education and Sport ${ }^{\circledR}$ (JPES). 2018; 59, 18, Supplement 1: 421-424.

\section{References}

1. Apanasenko GL, Popova LA, Maglevaniy AV. (2011), Sanologiya(Medichni aspekti valeologii) [Sanology (Medical aspects of valueology)], Kiev-Lviv, Ukraine.

2. Gavrilova NV. (2011), "Improving the functional and physical preparedness of the cyclists age 13-16 by using the methods of endogenous and hypoxic breathing in the preparatory period of annual macrocycle", Moloda sportivna nauka Ukrayini [Young sport science of Ukraine], Lviv, vol 15 (1), pp. 48-54.

3. Holovkina VV. (2020), Application of aquafitness elements and interval hypoxic training in system training of swimmers 11-12 years, Manuscript", [dissertation]. Mykhaylo Kotsyubynskyi Vinnytsia State Pedagogical University, Vinnytsia, Ukraine.

4. Kulikov MA. and Shastun SA. (1983), Statisticheskie metodi obrabotki rezultatov phiziologicheskih eksperimentov [Method of statistics], Visshaia shkola, Moscow, Russia.

5. Khodorovs'kij GI, Koliasko IV, Furkal Ie.S. (2006), Endogennogipoksichne dikhannia: teoriia i praktika [Endogenous hypoxic respiratory: Theory and Practice], Chernivtsi, Ukraine.

6. Furman YuM, Holovkina VV, Salnykova SV, Sulyma AS, Brezdeniuk OYu, Korolchuk AP, Nesterova SYu. Effect of swimming with the use of aqua fitness elements and interval hypoxic training on the physical fitness of boys aged 11-12 years. Pedagogics, psychology, medical-biological problems of physical training and sports. 2018; 22(4): 184-188. Doi: 10.15561/18189172.2018. 
7. Salnykova SV, Furman YuM, Sulyma AS, Hruzevych IV, Gavrylova NV, Onyschuk VYe, Brezdeniuk $\mathrm{OYu}$. Peculiarities of aqua fitness exercises influence on the physical preparedness of women 30-49 years old using endogenous-hypoxic breathing method. Pedagogics, psychology, medical-biological problems of physical training and sports. 2018; 22(4): 210-215. Doi: 10.15561/18189172.2018.0407

8. Sergiy Drachuk, Viktoriia Bohuslavska, Maryan Pityn, Yuriy Furman, Viktor Kostiukevych, Nataliia Gavrylova, Svitlana Salnykova, Tetiana Didyk, Energy supply capacity when using different exercise modes for young 17-19-year-old men, Journal of Physical Education and Sport ${ }^{\circledR}$ (JPES). 2018; 18(1): Art 33, 246-254.

9. Victoria Golovkina, Svetlana Salnukova. Comparative Characteristics of Functional Capability of 11-12 year-old Swimmers Connected with Their Gender and Possibilities of Its Improvement. Prace Naukowe Akademii im. Jana Długosza w Częstochowie Kultura Fizyczna. 2018; 1(XVII): 79-85.

10. Volodymyr Vitomskiy, Iryna Hruzevych, Svitlana Salnykova, Alla Sulyma, Volodymyr Kormiltsev, Yuriy Kyrychenko, Larysa Sarafinjuk. The physical development of children who have a functionally single heart ventricle as a basis for working physical rehabilitation technology after a hemodynamic correction. Journal of Physical Education and Sport ® (JPES). 2018;Volume 89, Issue No 18(2): 614-617.

11. Volodymyr Vitomskiy, Volodymyr Kormiltsev, Iryna Hruzevych, Svitlana Salnykova, Yurii Shevchuk, Yulia Yakusheva. Features of the physical development of children with functionally single heart ventricle as a basis of the physical rehabilitation technology after a hemodynamic correction. Journal of Physical Education and Sport ${ }^{\circledR}$ (JPES). 2018; 59, 18, Supplement 1: 421-424.

Цитування на цю статтю:
Фурман ЮМ, Головкіна ВВ, Сальникова СВ, Довгій ЮІ. Вплив елементів аквафітнесу й інтервального
гіпоксичного дихання на динаміку відновлення функції серцево-судинної системи плавців. Вісник
Прикарпатського університету. Серія: Фізична культура. 2020 Листоп 03; 35: 78-83

Відомості про автора:

Фурман Юрій Миколайович - доктор біологічних наук, професор, завідувач кафедри медико-біологічних основ фізичного виховання та фізичної реабілітації, Вінницький державний педагогічний університет імені Михайла Коцюбинського (Вінниця, Україна)

e-mail: furman-dok@ukr.net

https://orcid.org/0000-0002-5206-7712

Головкіна Вікторія Володимирівна - доктор філософії, галузь знань 01 Освіта / Педагогіка, спеціальність 017 Фізична культура і спорт, викладач кафедри фізичного виховання, Вінницький державний педагогічний університет імені Михайла Коцюбинського (Вінниця, Україна)

e-mail: akvavita72@gmail.com

https://orcid.org/0000-0001-9912-7754

Сальникова Світлана Володимирівна - кандидат наук з фізичного виховання і спорту, доцент, завідувач кафедри фізичного виховання та спорту, Вінницький торговельно-економічний інститут Київського торговельно-економічного університету (Вінниця, Україна)

e-mail: aqvasveta@ukr.net

https://orcid.org/0000-0003-4675-6105

Довгій Юрій Іванович - старший викладач кафедри фізичного виховання та спорту, Вінницький торговельно-економічний інститут Київського торговельно-економічного університету (Вінниця, Україна)

e-mail: sveta.parfilova@ukr.net

https://orcid.org/0000-0001-6963-9660
Information about the author:

Furman Yuriy Mykolayovych - Doctor of Biological Sciences, Professor, Head of the Department of Medical and Biological Fundamentals of Physical Education and Physical Rehabilitation, Vinnytsia Mykhailo Kotsiubynskyi State Pedagogical University (Vinnytsya, Ukrayina)

Golovkina Victoria Vladimirovna - Doctor of Philosophy, Field of Knowledge 01 Education / Pedagogy, specialty 017 Physical Culture and Sports, Lecturer of the Department of Physical Education, Vinnytsia Mykhailo Kotsiubynskyi State Pedagogical University (Vinnytsya, Ukrayina)

Salnikova Svitlana Volodymyrivna - Candidate of Sciences in Physical Education and Sports, Associate Professor, Head of the Department of Physical Education and Sports, Vinnytsia Institute of Trade and Economics of Kyiv National University of Trade and Economics (Vinnytsya, Ukrayina)

Dovhiy Yuriy Ivanovych - senior lecturer of the Department of Physical Education and Sports, Vinnytsia Institute of Trade and Economics of Kyiv National University of Trade and Economics (Vinnytsya, Ukrayina) 